\title{
Factors associated with initiation and exclusive breastfeeding at hospital discharge: late preterm compared to 37 week gestation mother and infant cohort
}

\author{
Jennifer Ayton ${ }^{1,2^{*}+}$, Emily Hansen ${ }^{1,2+}$, Stephen Quinn ${ }^{3+}$ and Mark Nelson ${ }^{1+}$
}

\begin{abstract}
Background: To investigate and examine the factors associated with initiation of, and exclusive breastfeeding at hospital discharge of, late preterm (34 ${ }^{0 / 7}-36^{6 / 7}$ weeks) compared to 37 week gestation $\left(37^{0 / 7}-37^{6 / 7}\right.$ week) mother and baby pairs.

Methods: A retrospective population-based cohort study using a Perinatal National Minimum Data Set and clinical medical records review, at the Royal Hobart Hospital, Tasmania, Australia in 2006.

Results: Late preterm and 37 week gestation infants had low rates of initiation of breastfeeding within one hour of birth, 31 (21.1\%) and 61 (41.5\%) respectively. After multiple regression analysis, late preterm infants were less likely to initiate breastfeeding within one hour of birth $(\mathrm{OR} 0.395 \% \mathrm{Cl} 0.1,0.7 \mathrm{p}=0.009)$ and were less likely to be discharged exclusively breastfeeding from hospital (OR $0.495 \% \mathrm{Cl} 0.1,1.0 \mathrm{p}=0.04)$ compared to 37 week gestation infants.

Conclusion: A late preterm birth is predictive of breastfeeding failure, with late preterm infants at greater risk of not initiating breastfeeding and/or exclusively breastfeeding at hospital discharge, compared with those infants born at 37 weeks gestation. Stratifying breastfeeding outcomes by gestational age groups may help to identify those sub-populations at greatest risk of premature cessation of breastfeeding.
\end{abstract}

Keywords: Exclusive breastfeeding, Initiation, Late preterm, Infant

\section{Background}

Late preterm infants (LPI), loosely classified by current literature as infants born $34^{0 / 7}-36^{6 / 7}$ weeks gestation (239 days through to 259 days) [1-3], are less studied and described within Australian literature than term infants. Consensus does not exist around the gestational age group classification for this sub group of preterm infants, often cited as moderately preterm, near term, mildly preterm with gestational age ranges between 32 through to 37 weeks.

\footnotetext{
* Correspondence: Jennifer.Ayton@utas.edu.au

${ }^{\dagger}$ Equal contributors

'School of Sociology and Social Work, University of Tasmania, Hobart, Australia

${ }^{2}$ Menzies Research Institute Tasmania, University of Tasmania, Hobart, Australia

Full list of author information is available at the end of the article
}

Late preterm births have contributed disproportionally to the rising incidence of preterm births within the last decade $[4,5]$, adding substantially to the overall impact on health care services, both in the acute, and within primary health care settings [4,6-8]. In Australia they make up $69 \%$ of all preterm births and $8.1 \%$ of all births [8] and are five times more common than births occurring before 32 weeks gestation [9]. Compared with infants born at, and within, the term gestational period $\left(37^{0 / 7}\right.$ weeks $(260$ days) through to $41^{6 / 7}$ weeks (294 days) [10], late preterm infants are at increased risk of neonatal morbidity, experiencing one or more short term and long term health outcomes (hypoglycaemia, hypothermia, jaundice, delayed oral feeding, readmission to hospital, transient tachypnea [1,11], neuro-developmental delays [12] and mortality) $[13,14]$. Despite the importance of breastfeeding for this

\section{Biomed Central}

(c) 2012 Ayton et al.; licensee BioMed Central Ltd. This is an Open Access article distributed under the terms of the Creative Commons Attribution License (http://creativecommons.org/licenses/by/2.0), which permits unrestricted use, distribution, and reproduction in any medium, provided the original work is properly cited. 
vulnerable population of infants, the breastfeeding outcomes of preterm infants are less well documented and monitored compared to term infant populations [15].

The World Health Organization (WHO) recommends early initiation (where the infant receives colostrum or is breastfeed within the first hour of birth) and exclusive breastfeeding up to 6 months for all infants [16]. Exclusive breastfeeding is the gold standard of infant nutrition, defined as the infant was fed breast milk only (including expressed breast milk, oral rehydration solutions, drops, syrups, vitamins, minerals, medicines) [17].

Those studies that have reported outcomes by gestational age have found that infants born at 35-36 weeks gestation are less likely to initiate breastfeeding, compared to infants born at 37-39 weeks gestation, $(88.2 \%$ compared to $92.0 \%$ respectively) [18]. Those infants born 35-36 weeks gestation had a lower incidence of breastfeeding at 6 months compared to those born $\geq 37-39$ weeks [18]. In the Pelotas birth cohort study, latepreterm infants were $10 \%$ more likely not to commence breastfeeding or receive breast milk within the first 24 hours of life than term infants [19].

Many factors are negatively associated with successful breastfeeding, resulting in delays in, and/or failure of, early breastfeeding initiation (within the first hour of birth) and reduced duration of exclusive breastfeeding for term infant populations including; mode of delivery (caesarean versus vaginal birth), mothers parity (primparous women), maternal smoking, insufficient milk supply, maternal obesity $[20,21]$. It is therefore important to identify potential modifiable factors that contribute to breastfeeding failure (initiation and exclusive) for late preterm infants in order to customise breastfeeding support strategies that can address these factors in the clinical setting.

The aim of this study is to describe and investigate the breastfeeding outcomes of a mother and infant cohort of a sub population of preterm infants, LPI $\left(34^{0 / 7}-36^{6 / 7}\right.$ weeks) compared to a 37 week gestation $\left(37^{0 / 7}-37^{6 / 7}\right)$ cohort and to identify the infant and maternal factors associated with initiation and exclusive breastfeeding at discharge amongst both cohorts.

\section{Methods}

\section{Design}

This was a retrospective population-based cohort study using a Perinatal National Minimum Data Set and hospital clinical medical records review.

\section{Setting and sample}

The study was conducted at the Royal Hobart Hospital (RHH), Tasmania, Australia, a 501-bed WHO/UNICEF Baby Friendly accredited facility and Tasmania's major teaching and tertiary referral centre for high and low risk obstetrics. The sample was purposefully selected from the larger Royal Hobart 2006 birth population systematically. Data on mother and infant pairs who had given birth within the calendar year of 2006 were obtained from the Tasmanian Perinatal National Minimum Data Set [22]. The Tasmanian perinatal data set is derived from the Australian National Perinatal Data Collection, which is core set of data elements endorsed by the $\mathrm{Na}$ tional Health Information Standards and Statistics Committee for mandatory collection and reporting of pregnancy and childbirth outcomes of mothers and babies.

\section{Inclusion criteria}

Live births (in 2006) born between $34^{0 / 7}$ through to $37^{6 / 7}$ weeks gestation (239-266 days since the first day of the mothers last menstrual period), surviving to hospital discharge and whose mothers had intended to breastfeed in the antenatal period.

\section{Exclusion criteria}

Infants with congenital abnormities, infants transferred in or out of the facility, and mothers who elected not to breastfeed were excluded.

\section{Definitions and terms used}

Infant gestational age was estimated by obstetric ultrasound and/or calculated using the first day of the mother's last normal menstrual period, documented in the mother's antenatal clinical medical records and verified against the Tasmanian perinatal data set.

Preterm birth defined as those infants born less than 37 completed weeks of gestation $\left(28^{0 / 7}\right.$ weeks through to (196 days) $36^{6 / 7}$ weeks gestation (259 days) from the mothers last menstrual period) [10]. Term birth defined as infants born from $37^{0 / 7}$ weeks (260 days) through to $41^{6 / 7}$ weeks (294 days) from the mother's last menstrual period [10]. For the purposes of this study the 37 week gestation cohort included infants born $37^{0 / 7}$ weeks $(260$ days) through to $37^{6 / 7}$ weeks gestation (266 days).

\section{Breastfeeding terms}

The terms used to measure the breastfeeding outcomes for this study are derived from the WHO recommended definitions [17]. 'Exclusive breastfeeding' is defined as the infant was fed breast milk only (including expressed breast milk, oral rehydration solutions, drops, syrups, vitamins, minerals, medicines). 'Initiation of breastfeeding' defined as the infant breastfed or received colostrum within one hour of birth [17]. Mothers' 'intention to breastfeed' was obtained from duplicate baby and mother clinical perinatal birth records and verified against the mothers' antenatal clinical medical records. 


\section{Data collection}

Mother and infant demographic variables, method of birth, Apgar scores, birth weight (grams), gestational age, parity (i.e. number of previous pregnancies excluding the current pregnancy), postcode, date of birth, discharge date/time electronically extracted from the Tasmanian Perinatal National Minimum Data Set, crosschecked twice against mother and infant medical records for validity and entered into an Microsoft Access data base. Breastfeeding practices (initiation of, and exclusive breastfeeding as per WHO recommended definitions described above) [17], were extracted from the maternal and infant clinical records and verified against the mother and infant discharge summary. Ethics approval was granted from Southern Tasmania Health and Medical Human Research Ethics Committee [H0009470].

\section{Data analysis}

Infant gestational age was dichotomised into 37 week group $\left(37^{0 / 7}-37^{6 / 7}\right.$ week gestation) and late preterm $\left(34^{0 / 7}-36^{6 / 7}\right.$ weeks gestation) and sample characteristics compared using $t$-tests or chi-squared tests as appropriate. Multivariable logistic regression was used to examine the associations between outcomes, initiation of breastfeeding and exclusive breastfeeding, and our predictor of interest preterm / 37 week gestation infants. These models were adjusted for potential confounding factors listed as footnotes in each table. All models were validated using the Hosmer-Lemeshow goodness of fit statistic. A p-value of 0.05 (two-tailed) is considered

\begin{tabular}{|c|c|c|c|}
\hline Variable & 37 weeks & 34-36 weeks & $p$ value \\
\hline Mean \pm SD & $\mathrm{n}=80$ & $n=67$ & \\
\hline \multicolumn{4}{|l|}{ Maternal } \\
\hline Parity & $1 \pm 1.3$ & $1 \pm 1.3$ & 0.48 \\
\hline Maternal smoking & 28 (38.9) & $23(38.3)$ & 0.95 \\
\hline Maternal age & $28.3 \pm 6.8$ & $27.3 \pm 5.9$ & 0.30 \\
\hline \multicolumn{4}{|l|}{ Infant } \\
\hline${ }^{\dagger}$ Caesarean birth & $47(57.5)$ & $41(61.2)$ & 0.56 \\
\hline Birth weight (grams) & $2944 \pm 462.3$ & $2556 \pm 488.7$ & $<0.001$ \\
\hline Apgar at one minute & $8 \pm 1.5$ & $8 \pm 1.7$ & 0.08 \\
\hline Multiple Birth & $6(7.5)$ & $4(6.0)$ & 0.71 \\
\hline${ }^{+\dagger}$ Initiated breastfeeding & $61(41.5)$ & $31(21.1)$ & $<0.001$ \\
\hline $\begin{array}{l}{ }^{\dagger \dagger} \text { Exclusive breastfeeding } \\
\text { at discharge }\end{array}$ & $67(83.7)$ & $40(59.7)$ & $<0.001$ \\
\hline
\end{tabular}

${ }^{\dagger}$ Caesarean birth combined data (elective and emergency lower uterine segment caesarean section).

${ }^{+}+$Initiated breastfeeding - breastfed or received colostrum within one hour of birth.

${ }^{+\dagger \dagger}$ Exclusive breastfeeding at discharge, within 24 hours of discharge. statistically significant. All statistical analysis was conducted using Stata version 10.

\section{Results}

Maternal and infant characteristics are summarized in Table 1. During this study period (2006) there were 1887 live births at the RHH, 1730 (92\%) were born between $37^{0 / 7}-42^{6 / 7}$ weeks gestation and $156(8 \%)$ were born preterm gestation $\left(28^{0 / 6}-36^{6 / 7}\right.$ weeks).

Infants born late preterm, $34^{0 / 6}-36^{6 / 7}$ weeks gestation represented $108(60 \%)$ of all preterm births within the study period. A total of $n=147$ (67 (46\%) late preterm and 80 (54\%) 37 week gestation infants) were eligible for inclusion in this study based on maternal intent to breastfeed, the infant was born between $34^{0 / 7}$ through to $37^{6 / 7}$ weeks gestation and survived to hospital discharge. Of these, 41 (61\%) late preterm births were born via lower uterine caesarean section (elective and emergency combined) (Table 1).

Initiation of breastfeeding within one hour of birth was significantly lower for late preterm infants 31 (21\%) when compared to 37 week gestation infants 61 (41\%) $(\mathrm{p}=<0.001)$ (Table 1). Late preterm infants born by lower uterine caesarean section were $80 \%$ less likely initiate breastfeeding within one hour of birth $(\mathrm{p}=<0.002)$ (Table 2).

Tables 2 and 3 show the univariable and multivariable model obtained by logistic regression for the factors associated with initiation of breastfeeding within one hour of birth and exclusive breastfeeding at discharge. Late-preterm infants were $70 \%$ less likely to initiate breastfeeding, and $60 \%$ less likely to be discharged exclusively breastfeeding from hospital when compared to 37 week gestation infants (Table 3).

\section{Discussion}

To our knowledge, this is the first time that the breastfeeding practices (initiation of and exclusive breastfeeding) of late preterm infants $\left(34^{0 / 7}-36^{6 / 7}\right.$ weeks) have been reported in the Australian context. The proportion of late preterm infants to commence breastfeeding was much lower than those reported for infants born at similar gestations in other international studies $[18,19]$. Late preterm infants were significantly less likely to initiate breastfeeding within one hour of birth, or to be discharged home exclusively breastfeeding, compared to infants in the 37 weeks group. In this study, an important factor for predicting breastfeeding failure was gestational age and a cesarean section birth, with those infants born between $34^{0 / 7}-36^{6 / 7}$ weeks gestation at highest risk of failure. Gestational age, namely a late preterm birth, is predictive of breastfeeding failure.

An unexpected finding from this study was the high proportion of late preterm infants delivered by a lower 
Table 2 Factors associated with ${ }^{+\dagger}$ initiation of breastfeeding; late preterm compared with 37 week gestation, infant and mother cohort

\begin{tabular}{|c|c|c|c|c|}
\hline Variable & Univariable OR $(95 \% \mathrm{Cl})$ & $p$ value & *Multivariable OR $(95 \% \mathrm{Cl})$ & $p$ value \\
\hline Preterm (34-36wk) & $0.3(0.1,0.5)$ & $<0.001$ & $0.3(0.1,0.7)$ & 0.009 \\
\hline Parity & $0.8(0.6,1.0)$ & 0.15 & $1.7(0.4,1.2)$ & 0.21 \\
\hline Maternal smoking & $1.1(0.5,2.3)$ & 0.73 & $1.1(0.4,2.8)$ & 0.79 \\
\hline Maternal age & $1.0(1.0,1.1)$ & 0.538 & $1.1(1.0,1.1)$ & 0.05 \\
\hline Birth weight, $g$ & $1.0(1.0,1.0)$ & 0.08 & $1.0(1.0,1.0)$ & 0.72 \\
\hline Apgar at one minute & $1.6(1.3,2.0)$ & $<0.001$ & $1.7(1.2,2.2)$ & $<0.001$ \\
\hline${ }^{\dagger}$ Caesarean birth & $0.3(0.1,0.7)$ & 0.004 & $0.2(0.1,0.6)$ & $<0.002$ \\
\hline Multiple birth & $0.86(0.21,3.62)$ & 0.84 & $0.5(0.1,2.8)$ & 0.41 \\
\hline
\end{tabular}

*Adjusted for maternal smoking, age, parity, infant birth weight, caesarean birth, multiple birth, Apgar at one minute.

${ }^{\dagger}$ Caesarean section, combined data, emergency and elective caesarean births.

${ }^{++}$Initiated breastfeeding, infant breastfed or received colostrum within one hour of birth.

uterine cesarean section (elective and emergency combined). In Australia, 30.8\% of women gave birth via caesarean section in 2006, increasing to $35.5 \%$ in 2009 $[23,24]$. Similar upward trends have been observed and reported in larger studies for other high income countries with the rising incidence of late preterm births being attributed to increasing obstetric intervention, namely caesarean section [4,5]. Late preterm infants delivered by caesarean section in this study were $80 \%$ less likely to initiate breastfeeding within one hour of birth $(\mathrm{p}=<0.002)$. Larger studies amongst term infant/ mother populations have suggested negative associations between a caesarean delivery (elective and emergency) and onset of lactation and milk transfer and volume produced $[21,25]$. Further, Cregan et al. found that $82 \%$ of women delivering prematurely experienced problems with initiation, and had significant reduction in the volume of milk produced [26]. The combination of a caesarean delivery and prematurity of the infant creates a complex feeding scenario. Compromised by the varying degrees of infant physiological and developmental maturity reported in other studies $[5,11,27]$, the late preterm infant and mother experience a cascade of events, such as ineffective sucking at the breast leading to poor intake of milk volume, delayed and low production of maternal milk, infant lethargy, sleepiness, hypoglycaemia and hypothermia. Efforts should be made to review clinical care policies and reduce the number of caesarean section deliveries so as to improve the late preterm mother and infant chances of initiating and maintaining exclusive breastfeeding.

In population terms, late preterm births represent the largest subset of preterm births born at this facility and nationally [8]. The size of this population alone is likely to impact on health outcomes and healthcare resources $[1,11,12,19,28]$. Indeed, it is worth considering what impact preterm infant populations have on national breastfeeding rates, where they are not currently reported separately [29]. Stratifying breastfeeding outcomes by gestational age may help to identify those sub-populations at greatest risk of premature cessation.

Late preterm infants present with subtle problems that predispose them to poor breastfeeding outcomes. Notably, they are less likely to initiate at birth and to be discharged exclusively breastfeeding. The combined complexity of a caesarean delivery, infant prematurity and breastfeeding exacerbates the potential for problems

Table 3 Factors associated with exclusive breastfeeding at discharge; late preterm compared with 37 week gestation, infant and mother cohort

\begin{tabular}{lcccc}
\hline Variable & Univariable OR $(\mathbf{9 5} \% \mathbf{C l})$ & p value & *Multivariable OR (95\% Cl) & p value \\
\hline Preterm (34-36wk) & $0.3(0.1,0.6)$ & $<0.001$ & $0.4(0.1,1.0)$ & $1.3(0.9,1.9)$ \\
Parity & $1.4(1.0,2.0)$ & 0.05 & $1.2(0.5,3.1)$ & 0.15 \\
Maternal smoking & $1.2(0.5,2.7)$ & 0.61 & $1.0(0.9,1.1)$ & 0.62 \\
Maternal age & $1.0(1.0,1.1)$ & 0.22 & $1.0(0.9,1.0)$ & 0.62 \\
Birth weight, g & $1.0(1.0,1.0)$ & 0.01 & $0.4(0.2,1.1)$ & 0.11 \\
${ }^{\dagger}$ Caesarean birth & $0.7(0.3,1.6)$ & 0.48 & $1.2(0.2,6.3)$ & 0.09 \\
Multiple birth & $0.9(0.2,3.5)$ & 0.84 & & 0.79 \\
\hline
\end{tabular}

*Adjusted for maternal smoking, age, parity, caesarean birth, infant birth weight, multiple births.

${ }^{\dagger}$ Caesarean section, combined data emergency and elective caesarean birth. 
for late preterm mothers and infants. A simple reminder for clinicians is; as gestational age decreases so does the chances of breastfeeding success.

The purpose of this article is to identify issues and areas for intervention, increase awareness and prompt a review of care policy and practices at the local and national levels. The data presented supports the current and accumulating evidence suggesting that infants born $34^{0 / 7}-36^{6 / 7}$ weeks gestation represent the largest preterm infant birth population and are at increased risk of adverse clinical outcomes and breastfeeding problems while in hospital and indeed potentially after discharge. The low proportion of late preterm infants successfully commencing breastfeeding within the first hour after birth and then being discharge home exclusively breastfeeding attests to the vulnerability of this population and a growing body of evidence pointing to the increased morbidity of these infants.

\section{Limitations}

The data for this study were taken from a single centre, thus providing a small study number and impacting on the generalisability of the findings. Data extraction and analysis was dependent on the quality of primary data sources from the Tasmanian perinatal database and clinical medical notes.

It was outside the scope of this study to compare late preterm to other term gestation infant groups such as $37^{0 / 7}$ through to $39^{6 / 7}$ weeks gestation. We recognized that 37 week gestation (now called 'early term') infants may still not have optimal breastfeeding initiation and exclusive breastfeeding rates when compared with infants born greater or equal to 39 weeks gestation.

\section{Conclusions}

Gestational age, namely a late preterm birth, is predictive of breastfeeding failure.

Late preterm infants are at greater risk of not initiating breastfeeding or exclusively breastfeeding at hospital discharge when compared to 37 week gestation infants. Gestational age and a caesarean delivery are modifiable risk factors negatively effecting breastfeeding success for mothers and infants. Infants born $34^{0 / 7}-36^{6 / 7}$ weeks gestation represent the largest preterm infant birth population within Australia. The size of this preterm birth sub-group alone warrants further investigation and closer monitoring, particularly in relation to breastfeeding outcomes. Stratifying breastfeeding outcomes by gestational age groups may help to identify those subpopulations at greatest risk of premature cessation.

The data presented in this study act as a necessary first step for further research exploring reasons for breastfeeding failure and what strategies are needed to support and facilitate successful and continued exclusive breastfeeding for late preterm infants and their mothers.

\section{Competing interests}

The authors declare that they have no competing interests.

\section{Authors' contributions}

JA carried out the conception and design and acquisition of all the data and support with the analysis and interpretation of the data, preparation and writing of the manuscript. SQ carried out data analysis, supported with the interpretation of the data and revision of the manuscript and prepared the statistical analysis section in the manuscript. EH and MN provided support with conception design and interpretation of the data and detailed revision of manuscript. All authors read and approved the final manuscript.

\section{Acknowledgements}

We would like to thank Dr Diane Phillips Associate Professor, School of Nursing and Midwifery, Deakin University, Australia; Professor Anne Gardner, School of Nursing, Midwifery and Nutrition, James Cook University, Australia; Associate Professor Peter Dargaville, Royal Hobart Hospital Tasmania, Honorary Member, Menzies Research Institute Tasmania for their contribution to the research.

\section{Funding}

JA received a writing bursary funded by the Commonwealth Department of Health and Ageing PHCRED Research Capacity Building Initiative Program at the Menzies Institute Tasmania, University of Tasmania.

\section{Author details}

${ }^{1}$ School of Sociology and Social Work, University of Tasmania, Hobart, Australia. ${ }^{2}$ Menzies Research Institute Tasmania, University of Tasmania, Hobart, Australia. ${ }^{3}$ Flinders Clinical Effectiveness, Flinders University, Adelaide, South Australia, Australia.

Received: 29 March 2012 Accepted: 2 November 2012 Published: 26 November 2012

\section{References}

1. Engle WA, Tomashek KM, Wallman C: "Late-preterm" infants: a population at risk. Pediatrics 2007, 120(6):1390-1401.

2. Raju TN, Higgins RD, Stark AR, Leveno KJ: Optimizing care and outcome for late-preterm (near-term) infants: a summary of the workshop sponsored by the National Institute of Child Health and Human Development. Pediatrics 2006, 118(3):1207-1214

3. Raju TN: Late-preterm births: challenges and opportunities. Pediatrics 2008, 121(2):402-403.

4. Davidoff MJ, Dias T, Damus K, Russell R, Bettegowda VR, Dolan S, Schwarz $\mathrm{RH}$, Green NS, Petrini J: Changes in the gestational age distribution among U.S. singleton births: impact on rates of late preterm birth, 1992 to 2002. Semin Perinatol 2006, 30(1):8-15.

5. Engle WA, Kominiarek MA: Late preterm infants, early term infants, and timing of elective deliveries. Clin Perinatol 2008, 35(2):325-341. vi.

6. Moster D, Lie RT, Markestad T: Long-term medical and social consequences of preterm birth. N Engl J Med 2008, 359(3):262-273.

7. Escobar GJ, Clark RH, Greene JD: Short-term outcomes of infants born at 35 and 36 weeks gestation: we need to ask more questions. Semin Perinatol 2006, 30(1):28-33.

8. Laws P: Number of births by selected gestational ages and year, Australia, 1997 to 2007, unpublished data. Sydney: AlHW National Perinatal Statistics Unit; unpublished 2010.

9. Saigal S, Doyle LW: An overview of mortality and sequelae of preterm birth from infancy to adulthood. Lancet 2008, 371(9608):261-269.

10. World Health Organization (WHO): International Statistical Classification of Diseases and Related Health Problems 10th Revision (ICD-10) Version for 2010. Geneva: WHO; 2010.

11. Bastek JA, Sammel MD, Pare E, Srinivas SK, Posencheg MA, Elovitz MA: Adverse neonatal outcomes: examining the risks between preterm, late preterm, and term infants. Am J Obstet Gynecol 2008, 199(4):367 e361-368. 
12. Chyi L, Lee HC, Hintz SR, Gould JB, Sutcliffe TL: School outcomes of late preterm infants: special needs and challenges for infants born at 32 to 36 weeks gestation. J Pediatr 2008, 153(1):25-31.

13. Ananth $C V$, Gyamfi $C$, Jain $L$ : Characterizing risk profiles of infants who are delivered at late preterm gestations: does it matter? Am J Obstet Gynecol 2008, 199(4):329-331.

14. Kramer MS, Demissie K, Yang H, Platt RW, Sauve R, Liston R: The contribution of mild and moderate preterm birth to infant mortality. Fetal and Infant Health Study Group of the Canadian Perinatal Surveillance System. JAMA 2000, 284(7):843-849.

15. Callen J, Pinelli J: A review of the literature examining the benefits and challenges, incidence and duration, and barriers to breastfeeding in preterm infants. Adv Neonatal Care 2005, 5(2):72-88. quiz 89-92.

16. WHO/UNCIEF: Global Strategy on Infant and Young Child Feeding. Geneva: WHO/UNICEF; 2003.

17. WHO/UNICEF: Indicators for Assessing Infant and Young Child Feeding Practices; Part 1 Defintions. Geneva: WHO/UNICEF; 2007.

18. Donath SM, Amir LH: The effect of gestation on initiation and duration of breastfeeding. Arch Dis Child Fetal Neonatal Ed 2008, 93(6):448-450.

19. Santos IS, Matijasevich A, Silveira MF, Sclowitz IK, Barros AJ, Victora CG, Barros FC: Associated factors and consequences of late preterm births: results from the 2004 Pelotas birth cohort. Paediatr Perinat Epidemiol 2008, 22(4):350-359.

20. Thulier D, Mercer J: Variables associated with breastfeeding duration. J Obstet Gynecol Neonatal Nurs 2009, 38(3):259-268

21. Scott JA, Binns CW, Oddy WH: Predictors of delayed onset of lactation. Matern Child Nutr 2007, 3(3):186-193.

22. Australian Institute of Health and Welfare (AIHW): Perinatal National Minimum Data Set, Perinatal National Minimum Data Set: National Health Data Dictionary. Cat. no. HWI 59. Canberra: AlHW; 2003.

23. Laws PJ, Hilder L: Australia's Mothers and Babies 2006: Perinatal statistics series no 22 Cat no PER 46. Sydney: AlHW National Perinatal Statistics Unit; 2008.

24. Li Z: MCNally L, Hilder L, Sullivan E A: Australia's Mothers and Babies 2009: Perinatal statistics series no 25 Cat no PER 52. Sydney: AlHW National Perinatal Epidemiology and Statistics Unit; 2011.

25. Dewey KG, Nommsen-Rivers LA, Heinig MJ, Cohen RJ: Risk factors for suboptimal infant breastfeeding behavior, delayed onset of lactation, and excess neonatal weight loss. Pediatrics 2003, 112(3 Pt 1):607-619.

26. Cregan MD, De Mello TR, Kershaw D, McDougall K, Hartmann PE: Initiation of lactation in women after preterm delivery. Acta Obstet Gynecol Scand 2002, 81(9):870-877.

27. Adams-Chapman I: Neurodevelopmental outcome of the late preterm infant. Clin Perinatol 2006, 33(4):947-964.

28. Khashu M, Narayanan M, Bhargava S, Osiovich H: Perinatal outcomes associated with preterm birth at 33 to 36 weeks' gestation: a population-based cohort study. Pediatrics 2009, 123(1):109-113.

29. Australian Institute of Health and Welfare: 2010 Australian National Infant Feeding Survey: Indicator Results. Canberra: Australian Institute of Health and Welfare; 2011.

doi:10.1186/1746-4358-7-16

Cite this article as: Ayton et al:: Factors associated with initiation and exclusive breastfeeding at hospital discharge: late preterm compared to 37 week gestation mother and infant cohort. International Breastfeeding Journal 2012 7:16.

\section{Submit your next manuscript to BioMed Central and take full advantage of:}

- Convenient online submission

- Thorough peer review

- No space constraints or color figure charges

- Immediate publication on acceptance

- Inclusion in PubMed, CAS, Scopus and Google Scholar

- Research which is freely available for redistribution 